Derleme Makalesi

\title{
Türkiye'de Kanıta Dayalı Tıp Rehber ve Protokol Çalışmaları: Sağlık Araştırmaları Genel Müdürlüğü ve Sağlık Hizmetleri Genel Müdürlüğü Örnekleri
}

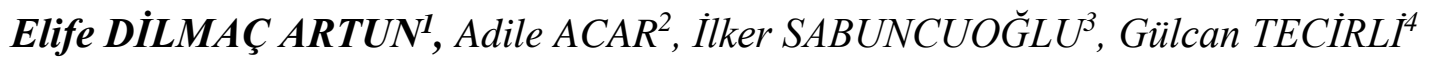

Öz

Klinik uygulama kılavuzları (rehber ve protokoller), belirli klinik durumlar için uygun sağlık bakımı hakkında hekim ve hasta kararlarına yardımcı olmak için geliştirilmiş sistematik açıklamalardır. Klinik uygulamayı dolayısıyla sağlık sonuçlarını iyileştirmek için, iyi geliştirilmiş Klinik Uygulama Kılavuzlarına ve etkili uygulama yöntemlerine ihtiyaç vardır. Özellikle son 30 yılda, klinik uygulama kılavuzlarının temelini oluşturan yöntemlerin geliştirilmesi, güncellenmesi, raporlanması, özel amaçlara göre uyarlanması, uygulanması ve değerlendirilmesi üzerine yapılan araştırmalar hız kazanmıştır. Türkiye Cumhuriyeti Sağlık Bakanlığı, Sağlık Hizmetleri Genel Müdürlüğü Daire Başkanlıklarından biri olan Araştırma Geliştirme ve Sağlık Teknolojisi Değerlendirme Dairesi Başkanlığı koordinasyonunda hazırlanan COVID-19 dışındaki klinik rehber ve protokollerin, sağlık olgularının yönetiminde kanıta dayalı iyi klinik uygulamaları tanımlaması, hasta bakım ve güvenlik standartlarını belirlemesi ile etkili ve sürdürülebilir stratejilerin seçiminde tüm sağlık profesyonellerine rehberlik etmesi hedeflenmektedir. Ülke düzeyinde, daha iyi klinik sonuçlara ulaşılmasına katkıda bulunmak için oluşturulan bu dinamik yapının gelişimi ile etkili ve verimli bir şekilde sürekliliğin sağlanması, ilgili tüm paydaşların desteği ile mümkündür.

Anahtar kelimeler: Klinik rehber, klinik protokol, klinik rehber geliştirme.

1. Araştırmacı, Dr., T.C. Sağlık Bakanlı̆̆ı, Sağlık Hizmetleri Genel Müdürlüğü, Araştırma, Geliştirme ve Sağlık Teknolojisi Değerlendirme Dairesi Başkanlığı, elife32@ hotmail.com, https://orcid.org/0000-0003-2572-442X

2. Araştırmacı, T.C. Sağlık Bakanlığı, Sağlık Hizmetleri Genel Müdürlüğü, Araştırma, Geliştirme ve Sağlık Teknolojisi Değerlendirme Dairesi Başkanlığı, adile.acar@saglik.gov.tr, https://orcid.org/0000-0002-1140-1390

3. Doktor, T.C. Sağlık Bakanlığı, Sağlık Hizmetleri Genel Müdürlüğü, Araştırma, Geliştirme ve Sağlık Teknolojisi Değerlendirme Dairesi Başkanlığ1, ilker.sabuncuoglu@saglik.gov.tr, https://orcid.org/0000-0002-8692-2502

4. Ebe, T.C. Sağlık Bakanlığı, Sağlık Hizmetleri Genel Müdürlüğü, Araştırma, Geliştirme ve Sağlık Teknolojisi Değerlendirme Dairesi Başkanlığ1, gulcan.tecirli@saglik.gov.tr, https://orcid.org/0000-0001-6244-3753

Gönderim Tarihi : 08.06.2021

Kabul Tarihi : 29.06 .2021

\footnotetext{
Atıfta Bulunmak Için:

Dilmaç Artun, E., Acar, A. Sabuncuoğlu, I. ve Tecirli, G.(2021). Türkiye'de Kanita Dayalı Tıp Rehber ve Protokol Çalışmalarl: Sağlık Araştırmaları Genel Müdürlüğü ve Sağlık Hizmetleri Genel Müdürlüğü Örnekleri, Eurasian Journal Of Health Technology Assessment, 5(1):45-54.
} 
Review Article

\author{
Evidence-Based Medicine Guidelines and Protocol Studies in Turkey: \\ Examples of the General Directorate of Health Research and the General \\ Directorate of Health Services \\ Elife DILLMAÇ ARTUN ${ }^{1}$, Adile ACAR ${ }^{2}$, İlker SABUNCUOĞLU ${ }^{3}$, Gülcan TECIRLI $I^{4}$
}

\begin{abstract}
Clinical practice guidelines and protocols are systematic statements developed to assist physician and patient decisions about appropriate health care for specific clinical situations. Well-developed Clinical Practice Guidelines and effective practice methods are needed to improve clinical practice and thus health outcomes. Especially in the last 30 years, research on the development, updating, reporting, adaptation according to special aims, application and evaluation of the methods that form the basis of clinical practice guidelines has gained momentum. The clinical guidelines and protocols, other than COVID-19, prepared under the coordination of the Research Development and Health Technology Evaluation Department, which is one of the departments of the General Directorate of Health Services, Ministry of Health of the Republic of Turkey, to define evidence-based good clinical practices in the management of health cases, to determine patient care and safety standards, and is aimed to guide all health professionals in the selection of effective and sustainable strategies. At the country level, it is possible to ensure continuity in an effective and efficient manner by the development of this dynamic structure created to contribute to the achievement of better clinical results, with the support of all relevant stakeholders.
\end{abstract}

Keywords: Clinical guideline, clinical protocol, clinical guideline development.

1. Researcher, PhD, Republic of Turkey Ministry of Health General Directorate of Health Services, R\&D and Health Technology Assessment Department, elife32@hotmail.com, https://orcid.org/0000-0003-2572-442X

2. Researcher, Republic of Turkey Ministry of Health General Directorate of Health Services, R\&D and Health Technology Assessment Department, adile.acar@saglik.gov.tr, https://orcid.org/0000-0002-1140-1390

3. Medical Doctor, Republic of Turkey Ministry of Health General Directorate of Health Services, R\&D and Health Technology Assessment Department, ilker.sabuncuoglu@saglik.gov.tr, https://orcid.org/0000-0002-8692-2502

4. Midwife, Republic of Turkey Ministry of Health General Directorate of Health Services, R\&D and Health Technology Assessment Department, gulcan.tecirli@saglik.gov.tr, https://orcid.org/0000-0001-6244-3753

Received : : 08.06 .2021

Accepted : 29.06.2021

\title{
Cite This Paper:
}

Dilmaç Artun E, Acar A, Sabuncuoğlu İ ve Tecirli G.(2021). Evidence-Based Medicine Guidelines and Protocol Studies in Turkey: Examples of the General Directorate of Health Research and the General Directorate of Health Services, Eurasian Journal Of Health Technology Assessment, 5(1):45-54. 


\section{Giriş}

Klinik uygulama kılavuzları, daha iyi klinik sonuçlara ulaşabilmek amacıyla, belirli klinik durumlarda, uygun sağlık hizmeti ile ilgili hekime ve hastaya karar vermede yardımcı olmak için sistematik olarak geliştirilmiş önemli araçlardır (Institute of Medicine, 1990). ABD Tıp Enstitüsü bu tanımını, 2011 yılında "Kanıtların sistematik olarak gözden geçirilmesi ve alternatif bakım seçeneklerinin yararları ve zararlarının değerlendirilmesi ile bilgilendirilen hasta bakımını optimize etmeye yönelik önerileri içeren ifadeler" olarak güncellemiştir. Bu çalışmada, klinik uygulama kılavuzları, klinik rehber ve protokol olarak ele alınmaktadır.

Klinik uygulamayı ve sağlık sonuçlarını iyileştirmek için, hem iyi geliştirilmiş Klinik Uygulama Kılavuzlarına (KUK) hem de bu kılavuzların etkili şekilde uygulanmasına ihtiyaç vardır (Turner vd., 2008). Özellikle son 30 yılda, klinik uygulama kılavuzlarının temelini oluşturan yöntemler üzerine, bunların geliştirilmesi, güncellenmesi, raporlanması, özel amaçlara göre uyarlanması, uygulanması ve değerlendirilmesi dâhil olmak üzere yapılan çalışmalar hız kazanmıştır (Kredo vd., 2016). Dünya Sağlık Örgütü (DSÖ) başta olmak üzere, İngiltere Ulusal Klinik Mükemmeliyet Enstitüsü (NICE: The National Institute for Clinical Excellence) ve Uluslararası Rehber A $\breve{g} 1$ (GIN: The Guidelines International Network) gibi kuruluşlar, uluslararası klinik uygulama kılavuz standartları hakkında çalışmalar yürütmektedirler.

Türkiye'de sağlık hizmetlerinin kalitesinin izlenmesi, değerlendirilmesi ve iyileştirilmesine yönelik yapısal çalışmalar ise Sağlık Bakanlığı tarafından, 2003 yılında Sağlıkta Dönüşüm Programı ile başlamıştır (Sağlık Bakanlığı, 2003). Programın sekiz temasından altıncısı "Nitelikli ve etkili sağlık hizmetleri için kalite ve akreditasyon" olarak belirlenmiştir. Sağlık kuruluşlarında hizmet sunumu kalitesini hedefleyen bu tema, daha sonra 2012 yılında klinik kaliteyi de kapsayan bir bileşene dönüşmüştür.

Sağlık Araştırmaları Genel Müdürlügü (SAGEM) de, bu kapsamda yürütülen yeniden yapılanma çalışmaları içerisinde, 2 Kasım 2011 tarih ve 28103 Sayılı Resmi Gazete'de yayımlanan "663 sayılı Sağlık Bakanlığı ve Bağlı Kuruluşlarının Teşkilat ve Görevleri Hakkında Kanun Hükmünde Kararname" ile kurulmuştur. SAGEM'e verilen görevler arasinda (663 Sayılı Kararname, md.12):

> Sağlık politikalarının belirlenmesi, izlenmesi, değerlendirilmesi, ülkenin sağlık düzeyinin yükseltilmesi ve sağlık hizmetlerinin geliştirilmesine yönelik ihtiyaç duyulan alanlarda araştırmalar yapmak veya yaptırmak,

$>$ Araştırma sonuçlarının ulusal veya uluslararası düzeyde yayımlanmasını sağlamak,

> Koruyucu, rehabilite edici hizmetler, teşhis ve tedavi metotlarının etkililiği, verimliliği, klinik, etik, sosyal, hukukî, organizasyonel ve ekonomik etkileri konularında değerlendirmeler yapmak veya yaptırmak, kanıta dayalı tıp uygulamaları ve klinik rehberler geliştirilmesi ve yaygınlaştırılması faaliyetlerini yürütmek,

gibi faaliyetler bulunmaktaydı. Yukarıda belirtilen görevlerden klinik rehberlerin geliştirilmesi ve yaygınlaştırılması ile sağlık teknolojisi değerlendirme konulu görevlerin yerine getirilebilmesi için de Genel Müdürlük çatısı altında, o zamanki ismi ile Sağlık Teknolojisi Değerlendirme Daire Başkanlığı kurulmuştur. Türkiye Sağlık Enstitüleri Başkanlığı Kurulması ile Bazı Kanun ve Kanun Hükmünde Kararnamelerde Değişiklik Yapılmasına Dair Kanun'a göre SAGEM 26.11.2017 tarihinde kapatılarak, yürüttüğü faaliyetler, Sağlık Hizmetleri Genel Müdürlügüne devredilmiştir. SAGEM'in kapatılmasının ardından klinik rehber ve protokol çalışmaları, sağlık teknolojisi 
değerlendirme çalışmaları ile birlikte Sağlık Hizmetleri Genel Müdürlüğünün çatısı altında devam etmektedir.

10 Ocak 2020 tarihinde yayımlanan "Sağlık Hizmetleri Genel Müdürlüğü Daire Başkanlıklarının Görevlerine Dair Yönerge" ile araştırma ve geliştirme faaliyetleri de Daire Başkanlığı uhdesine verilerek Daire Başkanlığının adı, Araştırma, Geliştirme ve Sağlık Teknolojisi Değerlendirme Dairesi Başkanlığ 1 olarak değiştirilmiştir. Yönergede, Daire Başkanlığının görevleri şu şekilde sıralanmaktadır (Sağlık Bakanlığı, 2020);

a) Bakanlığın ihtiyaçları doğrultusunda sağlık araştırmaları planlama, düzenleme ve geliştirme hizmetleri ile sağlık araştırmaları temel stratejiler ve eylem planları hizmetlerini yürütmek,

b) Genel Müdürlügün proje ve saha araştırmaları hizmetlerini yürütmek,

c) Sağlık teknolojisi tanımlama ve değerlendirme hizmetlerini yürütmek,

d) Kanıta dayalı tıp rehberlerinin hazırlanması hizmetlerini yürütmek,

e) Genel Müdür tarafından verilen diğer görevleri yapmak.

Daire Başkanlığının bu görevlerinin, Sağlık Bakanlığının 2019-2023 Stratejik Planının da belirtilen "Vatandaşlarımızın sağlığını korumak, geliştirmek ve herkesin hakkaniyet içinde kaliteli sağlık hizmetine erişmesini sağlamak" nihai amacına ulaşılmasında da önemli bir rolü bulunmaktadır (Sağlı Bakanlığı, 2018). Bu kapsamda, Sağlık Hizmetleri Genel Müdürlüğünün çatısı altında hazırlanan klinik rehber ve protokoller, sağlık olgularının yönetiminde kanıta dayalı iyi klinik uygulamaları tanımlamayı, hasta bakım ve güvenlik standartlarını belirlemeyi, etkili ve sürdürülebilir stratejilerin seçiminde tüm sağlık profesyonellerine rehberlik etmeyi hedeflemektedir. Bu amaçla, sağlık olgularının tanı, tedavi, rehabilitasyon ve izlem süreçleri ile koruyucu ve önleyici hizmetlerin yönetimine ilişkin uluslararası kanıtların yerel yapılara uyumu göz önünde bulundurularak hazırlanan rehber ve protokoller ile müdahale ve bakım süreçlerinin standart hale getirilmesi için çalışmalar yürütülmektedir (Sağlık Bakanlığı, 2021a).

Bu çalışmada, klinik rehberler ve protokoller ile ilgili ülkemizde bugüne kadar en kapsamlı ve uzun süreli çalışmaların yapıldığı, Araştırma, Geliştirme ve Sağlı Teknolojisi Değerlendirme Dairesi Başkanlığı çalışmaları özet bir şekilde sunularak, bu alanda sahada yapılan çalışmalara 1şık tutması amaçlanmaktadır.

\section{Klinik Rehber ve Protokoller}

Klinik rehber ve protokoller "belirli klinik durumlar için uygun sağlık bakımı hakkında hekim ve hasta kararlarına yardımcı olmak için geliştirilmiş sistematik açıklamalardır" (Cook vd., 1997; Field vd., 1990). Tek bir klinik durum veya olgu için yönetim adımlarını belirleyen kapsamlı bir dizi sistematik kriterin yer aldığı çalışmalardır. Hangi tanımlayıcı veya tarama testlerinin düzenlenmesi, tıbbi tedavinin nasıl sağlanacağı konusunda kısa talimatlar ya da cerrahi hizmetler; hastaların hastanede ne kadar kalması gerektiği ya da klinik uygulamaların detayları hakkında bilgi sunarlar. Aşağıda ilgili tanımlara ayrı ayrı değinilmektedir;

Klinik Rehber: Bir sağl1k konusunun tüm yönlerine ait (ör. sürveyans, tanı, halk sağlı̆̆1 müdahaleleri) tavsiyeleri içeren ve tüm kanıtların güçlü bilimsel sistematik taramalara dayandığı, hastalığın tüm alanlarının kapsandığı kanıta dayalı kılavuzlardır (WHO, 2014).

Klinik Protokol: Tek bir klinik durum veya olgunun yönetim adımlarını belirleyen kapsamlı bir dizi sistematik kriter sunan kılavuzlardır. Bu kriterlerin belirlenmesi dinamik bir süreç 
içinde gerçekleşir ve zaman içinde modifikasyonu da söz konusu olabilir. Klinik protokoller, bilimsel bütünlügü korurken açık, öz, net ve olabildiğince kısa olmalıdır (Merriman ve Dale, 2005).

Klinik Uygulama Algoritması (Tanı ve Tedavi Akış Şeması): Klinik bir sorunun değerlendirilmesi ve yönetimi hakkında, klinik karar verme için adım adım ilgili prosedürleri temsil eden grafik formatında yazılı bir kılavuzdur. Bir dizi klinik kararı temsil etmek, klinik karar vermeyi öğretmek ve hasta bakımını yönlendirmek için özel olarak hazırlanan uygun bir metin biçiminde hazırlanmış akış şemalarıdır. Temsili bir klinik algoritmada, klinik kararlar ayrıntılı olarak tarif edilmelidir. Bir algoritma beş adımda, bir algoritma kümesi de yedi adım dan oluşur (Margolis, 1983).

Klinik rehber ve protokoller, belirli bir prosedür izlenerek sistematik olarak kanıta dayalı geliştirilmeli, güncel bilimsel bilgilere dayanmalı ve günlük tıbbi uygulamalarda bu önerileri takip etmek mümkün olmalıdır. Ayrıca klinik rehber ve protokoller yeni kanıtlar ortaya çıktığında düzenli olarak güncellenmelidir. Kanıt temelli hazırlanan bu çalışmaların kabul görmüş standartları karşılamasına rağmen, uygulanmalarında istenen sonucun alınabilmesi için uygulayıcı sağlık profesyonelinin deneyimi ve istekliliği de önemlidir. Schiele ve arkadaşları tarafindan, 2001 ve 2006 yılları arasında yapılan bir çalışmada, yaşlı hastalarda kılavuzlar tarafından önerilen tedavilerin kullanımı ile mortalite arasında negatif bir ilişki gözlenmiştir. İlgili klinik rehbere uyum seviyesinin artmasının, yüksek riskli hastalarda, klinik sonuçlara olumlu etkisi olduğu görülmüştür (Schiele vd., 2009).

Klinik rehber ve protokoller, sağlık politikalarının oluşturulmasında büyük önem taşımaktadır. Bunlara uyumun mevcut kaynakların etkin kullanımı, sağlık hizmetlerinde israfın önlenmesi ve finansal koruma ile sürdürülebilirliğe katkısı önemli boyuttadır. Ayrıca bu çalışmalar bilimsel kanıtları ve olası fayda ve zararları ortaya koyarak hekim ve hastanın doğru karar verebilmelerine yardımcı olmakta, hasta sonuçlarını geliştirebilmekte, sağlık çalışanlarının eğitimine katkıda bulunmakta, hasta-sağlık çalışanları arasındaki iletişim kalitesini artırmakta, uygulamadaki varyasyonları azaltabilmekte ve sağlık hizmet kalitesini artırabilmektedir. Bu nedenle de son yıllarda, kanıt temelli yöntemlere duyulan ihtiyaç da giderek artmaktadır.

\section{Klinik Rehber Geliştirme Standartları}

Kılavuz geliştirme standartları, kuruluşların kanıta dayalı yüksek kaliteli kılavuzlar hazırlamalarına yardımcı olan araçlardır. ABD Tıp Enstitüsü ( IOM: Institute of Medicine ) ve NICE gibi kuruluşlar, kendi ülkelerine özgü güvenilir rehberler hazırlanabilmesi için standartlar geliştiren kuruluşlara örnek olarak verilebilir. 2002 yılında kurulan Uluslararası Rehber Ağ (GIN: Guideline International Network) ise 46 ülkeyi temsil eden 93 kuruluş ve 89 bireysel üyeden oluşan bir kılavuz geliştiriciler ağıdır (Ollenschläger vd., 2014). GIN, 2011 yılında da klinik kılavuzların geliştirilmesine ve değerlendirilmesine yardımcı olmak üzere mevcut literatürü gözden geçirerek kılavuz geliştirmede kullanılabilecek standartlar oluşturabilmek amacıyla bir fikir birliği süreci başlatmıştır (Ollenschläger vd., 2014). Dünya Sağlık Örgütü de 2010 yılında, Rehber Geliştirme El Kitabı yayımlamıştır (WHO, 2010). Bu çalışmalar sonucu ortaya çıkan yüksek kaliteli ve güvenilir bir klinik rehber geliştirme sürecinin temel bileşenleri şu şekilde sıralanmaktadır (WHO, 2010):

1. Rehber geliştirme grubunun oluşturulması,

2. Karar verme süreci,

3. Çıkar çatışmaları, mali destek ve sponsor organizasyon, 
4. Bir rehberin kapsamının belirlenmesi,

5. Yöntemler,

6. Kanit incelemeleri,

7. Rehber tavsiyeleri,

8. Kanit ve tavsiyelerin derecelendirilmesi,

9. Emsal değerlendirmesi ve paydaş görüşlerinin alınması,

10. Rehberin tamamlanması ve güncellenmesi.

Rehber geliştirmede, bir diğer önemli husus ise çok disiplinli uygulanabilirliğe sahip, uygulamaya hazır öneriler için verimli ve şeffaf bir yöntemin kullanıldığı kalite odaklı, kanıta dayalı k1lavuzlar üretmektir (Rosenfeld vd., 2012). Bu kapsamda, rehberlerin kalitesini değerlendirmek için 2003 yılında Rehberlerin Araştırma ve Değerlendirme Açısından İncelenmesi Girişimi (AGREE: The Appraisal of Guidelines for Research and Evaluation) tarafından 23 maddeden oluşan AGREE ölçeği geliştirilmiştir (Brouwers vd., 2016). 2009 yılında güncellenen AGREE II Ölçeğinin ana ve alt bileşenleri şunlardır (Brouwers vd., 2010):

1.Kapsam ve amaç;

a. Rehberin tüm hedef(ler)i belirgin şekilde tanımlanmıştır.

b. Rehberin kapsadığı klinik soru(lar) ayrıntılı olarak tanımlanmıştır.

c. Rehberin uygulandığı hastalar spesifik olarak tanımlanmıştır.

2. Paydaş katılımı;

a. Rehber geliştirme grubu, ilgili tüm profesyonel gruplardan bireyleri içerir.

b. Hastaların görüş ve tercihleri araştırılmıştır.

c. Rehberi hedef kullanıcıları açıkça tanımlanmıştır.

d. Rehber, son kullanıcılar arasında pilot olarak uygulanmıştır.

3. Geliştirme titizliği,

a. Kanıtların araştırılmasında sistematik metotlar kullanılmıştır.

b. Kanıtların seçiminde kullanılan kriterler açıkça belirtilmiştir.

c. Tavsiyelerin oluşturulmasında kullanılan metotlar açıkça tanımlanmıştır.

d. Tavsiyelerin formüle edilmesinde sağlı yararları, yan etkileri ve riskler dikkate alınmıştır.

e. Tavsiyeler ve destekleyici kanıtlar arasında açık bir bağlantı vardır.

f. Rehber, yayınlanmadan önce bağımsız uzmanlar tarafından gözden geçirilmiştir.

g. Rehberin güncellenmesi için bir prosedür sağlanmıştır.

4. Sunumun netliği,

a. Tavsiyeler, kesin ve açıktır.

b. Durumun yönetimi için farklı seçenekler açık bir şekilde sunulmuştur.

c. Temel tavsiyeler kolaylıkla tanımlanabilir.

5. Uygulanabilirlik,

a. Rehber, uygulama araçlarıyla desteklenir.

b. Önerilerin uygulanmasında potansiyel organizasyonel engeller tartışılmıştır.

c. Önerilerin uygulanmasının potansiyel maliyet sonuçları dikkate alınmıştır.

d. Rehber, gözetim ve/veya denetim için temel gözden geçirme kriterleri sunmaktadır.

6. Editoryal bağımsızlık,

a. Rehber, editoryal olarak fonlama organından bağımsızdır. 
b. Rehber geliştirme üyelerinin çıkar çatışmaları kaydedilmiştir.

\section{Klinik Rehber ve Protokol Çalışmaları}

Ülkemizde de Sağlık Bakanlığı çatısı altında, (i) ihtiyaç duyulan rehber ve protokolleri bir platformda toplayıp merkezileştirerek erişilebilirliği kolaylaştırmak, (ii) sunulan sağlık hizmetlerini kanıta dayalı rehberler üzerinden standartlaştırarak sağlık hizmet kalitesini geliştirmek ve iyileştirmek, (iii) eşitsizlikleri ve israfı önlemek, (iv) sağlık profesyonellerine klinik kalite ölçütlerini takip edebilecekleri bir kaynak oluşturmak amacıyla, kanıta dayalı klinik rehber ve protokoller hazırlanmaktadır. Bu klinik rehber ve protokollerin kullanımı ile ilgili bir zorunluluk olmayıp, gönüllülük esasına dayanmaktadır.

Hazırlanacak klinik rehber ve protokollerde sağlı olguları Ulusal Hastalık Yüküne göre belirlenmektedir. Klinik rehber ve protokoller, öncelikle tüm sağlık profesyonellerine, sağlık hizmeti kullanıcılarına ve yöneticilerine yönelik olarak hazırlanmaktadır. Ayrıca, bu rehber ve protokoller, Daire Başkanlığı koordinasyonunda uzmanlık derneği /meslek kuruluşu, üniversite hastaneleri, eğitim araştırma hastaneleri ve şehir hastanelerinin alanında uzman profesyonellerinden oluşan multidisipliner bir ekip tarafından hazırlanmakta ve yeni gelen kanitlar doğrultusunda güncellenmektedir. Tamamlanan klinik protokoller ve rehberler, Genel Müdürlük Yayın Komisyonu tarafından incelendikten sonra yayın numarası ve ISBN numarası alınarak Sağlık Hizmetleri Genel Müdürlüğü, Araştırma, Geliştirme ve Sağlık Teknolojisi Daire Başkanlığı ve Sağlıkta Kalite ve Akreditasyon Daire Başkanlığının web sayfalarında yayımlanmaktadır. Tablo 1'de SAGEM döneminde (2012-2017) yayımlanan klinik protokoller, Tablo 2'de SHGM'ne geçiş sonrası (2017-2020) yayımlanan klinik protokol/ rehberler ve Tablo 3'de ise halen çalışmaları devam eden klinik rehber ve protokollerin listeleri sunulmaktadır (Sağlık Bakanlığı, 2021a).

Tablo 1. SAGEM Döneminde (2017) Yayımlanan Klinik Protokoller

\begin{tabular}{|l|l|}
\hline$>$ Prostat Kanseri \\
\hline$>$ Katarakt Cerrahisi \\
\hline$>$ Diz Artroplastisi \\
\hline$>$ Kalça Artroplastisi \\
\hline$>$ İnme \\
\hline$>$ KOAH
\end{tabular}

Tablo 2. SHGM'ye Geçiş Sonrası (2018- 2020 ) Yayımlanan Klinik Protokol/ Rehberler

\begin{tabular}{|l|l|}
\hline Protokoller \\
\hline$>$ Anksiyete Bozuklukları \\
\hline$>$ Alzheimer ve Diğer Demans Hastalıkları \\
\hline$>$ Demir Eksikliği ve Demir Eksikliği Anemisi \\
\hline$>$ Diyabet Tedavi ve İzlem \\
\hline$>$ Epilepsi \\
\hline$>$ Hipertansiyon \\
\hline$>$ Koroner Arter Hastalığ \\
\hline$>$ Kolorektal Kanseri \\
\hline$>$ Kronik Böbrek Hastalığı \\
\hline$>$ Mide Kanseri \\
\hline$>$ Migren \\
\hline$>$ Pnömokonyozlarda Sağlık Gözetimi, Klinik Tanı, Kayıt, Bildirim ve İzlem \\
\hline
\end{tabular}




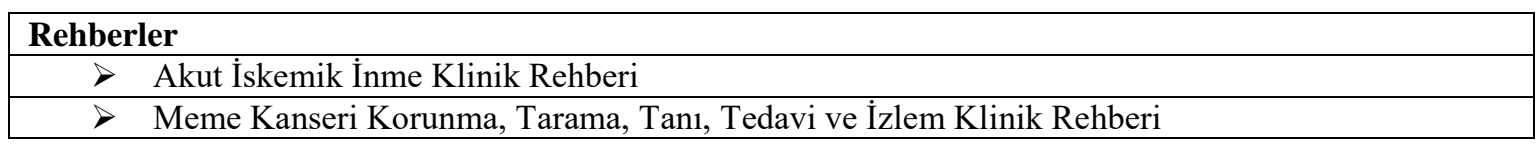

Tablo 3. 2021 İtibariyle Çalışmaları Devam Eden Klinik Protokoller

\begin{tabular}{|l|r|}
\hline$>$ Astım & $>$ Geriatri \\
\hline$>$ Bağımlılık Tanı Tedavi ve İzlem & $>\begin{array}{l}\text { Karaciğer Nakli Canlı Donör Seçimi ve } \\
\text { Yaşam Boyu Takip Süreci }\end{array}$ \\
\hline$>\begin{array}{l}\text { Böbrek Nakli Canlı Donör Seçimi ve Yaşam } \\
\text { Boyu Takip Süreci }\end{array}$ & $>$ Karaciğer Sirozu \\
\hline$>$ Diş Çene İmplantı Uygulamaları & $>$ Obezite Cerrahisi \\
\hline$>$ Diz ve Kalça Artroplastisi (Revizyon) & $>$ Sezaryen Seçimi \\
\hline$>\begin{array}{l}\text { Diyaliz Tedavi Yöntemlerinin Seçimi ve } \\
\text { Değiştirilmesi }\end{array}$ & $>$ Troid Kanseri Tanı Tedavi ve İzlem \\
\hline$>$ Erken, Geç Ortodontik Tedavilere Yaklaşım
\end{tabular}

Araştırma, Geliştirme ve Sağlık Teknolojisi Dairesi Başkanlığı tarafından hazırlanan klinik rehber ve protokollerin yaygınlaştırılması ve kullanımı ile ilgili çalışmalar, Sağlıkta Kalite ve Akreditasyon Daire Başkanlığı ile iş birliği içerisinde yürütülmektedir. Klinik uygulamalarla ilgili iyileştirilebilecek alanların belirlenerek sürekli iyileşmenin sağlanması amacıyla da hazırlanan klinik rehber ve protokollerin konusunu oluşturan sağlık olguları ile ilgili, Sağlıkta Kalite ve Akreditasyon Dairesi Başkanlığı tarafından belirlenen kalite indikatörleri, Klinik Kalite Ölçme ve Değerlendirme rehberlerinde tanımlanan kurallar çerçevesinde ve sahadan toplanan verilerle izlenmektedir (Sağlık Bakanlığı, 2021b).

\section{Kisitlılıklar}

Çalışma da sadece, Araştırma, Geliştirme ve Sağlık Teknolojisi Değerlendirme Daire Başkanlığı tarafından Sağlık Araştırmaları Genel Müdürlüğü ve Sağlık Hizmetleri Genel Müdürlüğü bünyesinde hazırlanan klinik rehber ve protokollere yer verilmiştir. Bakanlık çatısı altında yürütülen başka çalışmalarında olabileceği de göz önünde bulundurulmalıdır. Halk Sağlığı Genel Müdürlüğü tarafindan da 1. ve 2. basamak sağlık hizmeti sunan sağlık kurumlarına yönelik hazırlanan klinik rehberlerin olduğu da unutulmamalıdır (Halk Sağlığı Genel Müdürlügü, 2021).

\section{Sonuç}

Klinik kalitenin iyileştirilmesi için gerekli yapısal dönüşüm 2003 yılında, Sağlıkta Dönüşüm programı içerisindeki hedefler arasında yer almıştır. Sonrasında, 2012 yılında 663 sayılı Kanun Hükmünde Kararname ile kurumsal bir yapıya kavuşturulmuştur. Yine aynı yıl klinik kalite programı ile klinik kaliteye verilen önem iyice ön plana çıkmaya başlamıştır. Bu kapsamda SAGEM ve SHGM bünyesinde, klinik rehber ve protokollerin hazırlanmas1, yaygınlaştırılması ve izlenmesi çalışmaları dinamik bir yapıya bürünerek devam etmektedir. "Vatandaşlarımızın sağlığını korumak, geliştirmek ve herkesin hakkaniyet içinde kaliteli sağlık hizmetine erişmesini sağlamak" nihai amacına hizmet eden ve uzun zamandır büyük özveri ve emekle hazırlanan bu yapının sürekli gelişimi ve devamlılığının sağlanması daha iyi klinik sonuçlar için elzemdir. Daha iyi klinik sonuçlar için klinik kalite kültürünün geliştirilebilmesi, mevcut kaynakların etkin kullanılabilmesi, sağlik sisteminin sürdürülebilirliği, bu sistemin ilgili tüm taraflarca sahiplenilmesi ve desteklenmesi ile mümkündür. 


\section{Kaynakça}

1. Brouwers, MC., Kerkvliet, K., Spithoff, K., on behalf of the AGREE Next Steps Consortium (2016). The AGREE Reporting Checklist: a tool to improve reporting of clinical practice guidelines. BMJ 2016;352:i1152. doi: 10.1136/bmj.i1152.

2. Brouwers, MC., Kho, ME., Browman, GP., et al \& AGREE Next Steps Consortium (2010). AGREE II: advancing guideline development, reporting and evaluation in health care. CMAJ: Canadian Medical Association journal = journal de l'Association medicale canadienne, 182(18), E839-E842. https://doi.org/10.1503/cmaj.090449.

3. Cook, DJ., Greengold, NL., Ellrodt, AG. (1997). The relation between systematic reviews and practice guidelines. Ann Intern Med 1997;127:210-6.

4. Field, MJ., Lohr, KN., et al. (1990) Clinical Practice Guidelines.In: 1st ed. Washington DC: National Academy Press 1990:1-166.

5. Halk Sağlığı Genel Müdürlüğü https://hsgm.saglik.gov.tr/tr/yayinlarimiz/rehberler.html, Erişim:04.05.2021.

6. Institute of Medicine (1990). Clinical practice guidelines: directions of a new program. Committee to advise the public health service on clinical practice guidelines. Field MJ, Lohr KN, eds. Washington DC: National Academy Press, 1990.

7. Kredo, T., Bernhardsson, S., Machingaidze, S. et al (2016). Guide to clinical practice guidelines: the current state of play. Int J Qual Health Care. 2016 Feb;28(1):122-8. doi: 10.1093/intqhc/mzv115. Epub 2016 Jan 20. PMID: 26796486; PMCID: PMC4767049.

8. Margolis, CZ. (1983). "Uses of Clinical Algoritms" JAMA:The Journal of the American Medical Association 249(5):627-632.

9. Merriman, LM. and Dale, J. (2005). Clinical protocols, in Clinical Skills in Treating the Foot (Second Edition), Churchill Livingstone, 2005. ISBN 9780443071133, https://doi.org/10.1016/B978-0-44307113-3.50001-9.

10. Ollenschläger, G., Marshall, C., Qureshi, S. et al. (2002). Guidelines International Network (G-I-N). Improving the quality of health care: using international collaboration to inform guideline programmes by founding the Guidelines International Network (G-I-N). Qual Saf Health Care. 2004;13:455-60. [PMID: 15576708].

11. Rosenfeld, MR., Shiffman RN., Robertson, P. (2012). Clinical practice guideline development manual: A quality-driven approach for translating evidence into action. Otolaryngology-Head and Neck Surgery.148(1S) S1-S55.

12. Schiele, F., Meneveau, N., Seronde, MF. et al. (2009). Reseau de Cardiologie de Franche Comte. Changes in management of elderly patients with myocardial infarction. Eur Heart J. 2009 Apr;30(8):987-94. doi: 10.1093/eurheartj/ehn601. Epub 2009 Jan 27. PMID: 19176538.

13. Sağlık Bakanlığı (2003). Sağlıkta Dönüşüm Programı. Ankara

14. Sağlık Bakanlığı (2018). 2019-2023 Stratejik https://sgb.saglik.gov.tr/Eklenti/35748/0/stratejikplan2019-2023pdf.pdf, Erişim:04.04.2021.

15. Sağlık Bakanlığı (2020). Sağlık Hizmetleri Genel Müdürlüğü Daire Başkanlıklarının Görevlerine Dair Yönerge. 2021 (https://shgm.saglik.gov.tr/Eklenti/39421/0/saglik-hizmetleri-genel-mudurlugu-dairebaskanliklarinin-gorevlerine-dair-yonergepdf.pdf), Erişim:03.04. 2021.

16. Sağlık Bakanlığı (2021a). Klinik Rehber ve Protokoller. https://shgmargestddb.saglik.gov.tr/TR64023/calismalarimiz.html, Erişim: 21.05.2021.

17. Sağlık Bakanlığı (2021b). Klinik Kalite Ölçme Değerlendirme Rehberi, https://shgmklinikkalite.saglik.gov.tr/Eklenti/40774/0/klinik-kalite-e rehberpdf.pdf, Erişim: 20.04.2021.

18. Turner, T., Misso, M., Harris, C. et al. (2008). Development of evidence-based clinical practice guidelines (CPGs): comparing approaches. Implementation Sci 3, 45 (2008). https://doi.org/10.1186/1748-5908-345E.T. $\quad$ https://implementationscience.biomedcentral.com/articles/10.1186/1748-5908-3-45, Erişim:28.05.2021 
19. WHO (2014). WHO handbook for guideline development, $2 . \quad$ Edition. https://www.who.int/publications/guidelines/handbook_2nd_ed.pdf, Erişim:08.03.2021.

20. WHO (2010). WHO Handbook for Guideline Development. https://www.who.int/hiv/topics/mtct/grc_handbook_mar2010_1.pdf, Erişim:20.03.2021. 